\title{
A SECA E O COMBATE AOS FATORES DESESTABILIZADORES DA ECONOMIA AGRICOLA DO NORDESTE*.
}

\author{
Manuel Correia de O. Andrade**
}

\section{REDIMENSIONANDO O PAPEL DA SECA NA CRISE SÓCIO-ECONOOMICA NORDESTINA}

O Nordeste é considerado como uma regiầo que possui grande desequilíprio em sua economia, atribuindo-se geralmente este desequilíbrio à influência de condições naturais adversas, sobretudo ao clima semi-árido e às secas que ocorrem com grande intensidade, quase sempre uma vez em cada ano. No momento esta crença se agudiza, de vez que acabamos de viver uma seca que flagelou a região por mais de cinco anos, sendo considerada por estudiosos, como Gileno de Carli, a maior do século. Além da seca, vive a região, como o pals, uma grande crise econômica que tem provocado o fechamento de numerosas unidades industriais, aumentando consideravelmente o indice de desemprego, tanto na cidade como no meio rural. A coincidência entre a grande seca e a grande crise tem levado numerosas pessoaš a aćreditar que o desequilíbrio econômico é conjuntural e que, passada a seca e superada a crise, a economia nordestina retomará seu ritmo de crescimento.

Esta crença porém não tem nenhum fundamento, de vez que em numerosas regiões do mundo dominam climas adversos, obrigando o homem a regularizar sua ação produtiva, levando em conta as características dos mesmos; a crise que atinge o Nordeste de forma intensa, se deve a um sistema econômico alienado que impede o desenvolvimento real, com implicações não apenas econômicas, mas também sociais e ecológicas sobre a região.

Assim, nos países secos mais desenvolvidos, dispõe a população de estruturas e de conhecimentos que permitem desenvolver as culturas xerófitas e a irrigação, usando águas de rios perenes, de poços profundos ou armazenadas por represas e cisternas, para garantir o abastecimento e as atividades agrárias; dispõe de técni-

* Texto base, rexisado e corrigido, da conferência de abertura do "f Encontro sobre as Alternativas Econômico-Sociais para o Desenvolvimento do Nordeste", realizado em João Pessoa (Para(ba), 25-29,3,1984, organizado pelo Departamento de Economia e o Grupo de Assessoria, Planejamento e Pesquisa Econômica (GAPPE), da Universidade Federal da Parafba (UFPb).

* * Geógrafo, historiador e escritor, Professor Titular do Departamento de Ciências Geográficas da Universidade Federal de Pernambuco (UFPe.). 
cas que permitem o desenvolvimento de culturas adaptadas ao clima seco, podendo sobreviver a grandes estiagens, assim como de cultura de plantas de ciclo vegetativo curto na estação chuvosa. Ainda se pode armazenar alimentos e forragens na estação chuvosa para o consumo na estação seca.

$\mathrm{Na}$ verdade, os grandes problemas do Nordeste resultam muito mais de condições sócio-culturais e econômicas do que de condições naturais. Eles são estruturais, embora em alguns períodos sejam exacerbados,por ocorrências conjunturais. O Nordeste se vê freiado em seu desenvolvimento em conseqüência do sistema de colonização, baseado na exploração da terra, sob a forma de grandes propriedades e na política de incentivo, de estímulo à prorlução agrícola para o mercado externo. Mesmo quándo o mercado interno das 1 gióes ricas passa a absorver estes produtos, as estruturas existentes continuam a fortalecer a permanência do latifúndio e da concentração da renda, em detrimento dos interesses do grosso da produção. Ela é conseqüência também de um processo de modernização tecnológica e social, que não é feita consultando os desafios da região, mas através da tränsposição de experiências estrangeiras que respondiam a outros desafios e de uma política de modernização das velhas estruturas, vișando torná-las viáveis, evitando as reformas que realmente beneficiariam o país e a região.

\section{A MODERNIZAÇÄO DOLOROSA DOS PROGRAMAS GOVERNAMENTAIS}

Para melhor fazer compreender o que entendemos por modernizaçäo, que consolida as velhas estruturas e agudiza os problemas, podemos analisar alguns programas, como:

- o PROÁLCOOL,que vem estimulando a implantação de grandes destilarias, com baixíssimos investimentos por parte dos grupos econômicos que se instalam, sob o pretexto de que elas resolverão os problemas de abastecimento de produtos energéticos e contribuirão para o equilíbrio do balanço de pagamento. Não se leva em conta a grande ação poluidora da indústria alcooleira, que degrada os rios com o lançamento, em seus leitos, do vinhoto, nem que a expansão dos canaviais para abastecer as destilarias vem sendo feita em detrimento da produção de alimentos, dificultando e agravando o problema de abastecimento alimentar da população.

- o programa de racionalização e modernizaçăo da indústria açucareira, que vem provocando problemas idênticos, fazendo com que a modernização e a relocalização das usinas tragam, cada vez mais, dificuldades à agricultura de alimentos que não goza dos favores e subsídios oficiais, não podendo, em conseqüência, competir com a cana-de-açúcar.

- O processo de pecuarização, em rápido avanço, que da mesma forma que a política alcooleira e açucareira, vem criando sérios problemas sociais. Atra. 
vés deste processo, o proprietário da terra e criador passa a cultivar áreas com gramíneas e/ou leguminosas resistentes à seca e a acumular alimentos na estação chuvosa para consumo no estio, sobretudo em silos-trinchieiras. Com estas medidas, executadas geralmente graças a empréstimos de bancos oficiais e a juros baixos, o pecuarista liberta-se da necessidade de fornecer terras aos agricultores sem terra, para que cultivem milho, feijão e algodão em associação e que, após a colheita, liberem a terra, o antigo "roçado", para que o gado se alimente com o restolho destas plantas. Ora, ocorre que estes agricultores perderam a possibilidade de cultivar a terra, por deixarem as mesmas de ser arrendadas a eles, e, tiveram que migrar para as áreas novas, mas já apropradas' - Sul do Piauí, Oeste do Maranhão e Bahia -, onde vão trabalhar como assalariados ou como moradores dos grandes fazendeiros que se apossaram de vastas áreas, através da compra ou da grilagem. A política de modernização da pecuária deveria ter sido acompanhada de uma política de remoção e localização destes agricultores em terras próprias - pequenas propriedades familiares - ou em terras de cooperativas, de que eles se tornassem cotistas. Resolver-se-ia assim, ao invés de se agravar, a questão social. Questão que cada dia se torna mais séria e que exige a mais rápida solução se quisermos evitar a eclosão de uma verdadeira convulsão social. Na região semi-árida, pode-se observar a mesma tendência à conservação das estruturas sociais existentes, através de programas governamentais com projetos de empréstimos para construção de cercados, de poços, de açudes, de currais e de casas de fazenda a proprietários que tenham de 20 a 500 hectares. Estes empréstimos são feitos a juros.inferiores à inflacăo e a longo prazo, ao mesmo tempo em que se deixa os proprietários com menos de 20 ha sem uma assistência à altura. Observa-se ainda que os empréstimos agrícolas são feitos com uma grande preocupação teórica com o crescimento da produtividade, obrigando-se a que grande parte dos recursos emprestados sejam aplicados na aquisição de adubos e inseticidas, dificultando o uso do recurso emprestado para cobrir as despesas mais prementes do pequeno produtor. Emprego que naturalmente tornaria mais facil ao mesmo saldar o débito na ocasião do pagamento.

De grande importância é a intensificação do uso da água do rio São Francisco e dos grandes açudes para irrigação. Ocorre porém que esta política vem prejudicando os pequenos posseiros e beneficiando, sobretudo, empresas de outras regiões do país e aos grandes proprietários da área. Assim, no sub-médio São Francisco, a maior porção da área irrigada é entregue a grandes empresas ou a médios e grandes proprietấrios que desenvolvem culturas nobres, visando o abastecimento dos grandes centros urbanos do país, em detrimento das culturas de gêneros alimentícios, feitas por pequenos produtores. Dentre as culturas nobres, salientam-se a cebola, o alho, o tomate, o melão, a melancia e a uva. Apesar da experiência positiva da cooperativa de Bebedouro II, no município de Petrolina, a área beneficiada por infra-estrutura de irrigação, entregue a cooperativas, é insig: 
nificante, face à ocupada por empresas e grandes proprietários. E para implantar estas obras ligadas à irrigação e para construir as barragens que cobrem vários quilômetros de terras agrícolas, são desapropriados milhares de posseiros - pequenos produtores - que se vêem no dilema de migrar ou de se marginalizar nas cidades médias e grandes. Poucos são os que ficam nas áreas onde eram posseiros, quase sempre transformados em assalariados agrícolas. Aí também gozam de grandes vantagens as companhias agro-industriais, que podem adquirir o produto agrícola (a matéria prima), sem investir na compra de terras, através de contratos de venda antecipada da produção como condição para a agricultura obter os empréstimos nos bancos oficiais, como ocorre sobretudo com o tomate.

\section{OS CAMINHOS A PERCORRER}

- O combate aos desequilíbrios existentes e que se vão acentuando, é muito dificil; prejudicam a região e a majoria da população, beneficiam a grupos econômicos poderosos que exercem pressão sobre os órgãos governamentais e se usufruem dos programas aplicados pelos mesmos. $E$, naturalmente, os grupos hegemônicos das classes dominantes e as grandes empresas que atuam em escala nacional e multi-nacional, não só exercem pressão direta como utilizam os meios de comunicação, para que as apresentem como agentes do progresso e do desenvolvimento e como órgãos cuja ação vai trazer benefícios à região. Criam assim uma ideologia que é transferida às várias camadas sociais e que "legitima" sua ação. Uma modificação das diretrizes dominantes se torna assim difícil e só pode ser executada através de uma forte polf́tica de esclarecimento e de educação do povo.

Dentro dos quadros institucionais dominantes, teria que lançar uma política de conscientização da população para a necessidade de uma série de medidas que modificassem as estruturas institucionais, a iniciar-se com o problema da propriedade da terra, que deveria ser legalizada urgentemente em atendimento aos posseiros que detêm o controle das áreas que cultivam, a fim de que juntassem à posse o domínio da terra, assim como que se fizesse desapropriação das áreas dos grandes propriétários que iriam ser beneficiados pela construção de obras públicas. Por exemplo: ao se construir um grande açude ou uma represa, não se deveria exigir do proprietário da terra apenas o reconhecimento do direito à servidão e ao uso da água pelos pequenos proprietários e vizinhos, mas também se fazer a desapropriação daquelas áreas que fossem se tornar irrigável com a construção da represa. Estas áreas desapropriadas deveriam ser divididas com agricultores que se comprometessem, durante o período de utilização das mesmas, a cultivar os produtos necessários ao abastecimento local e regional, dentro de técnicas conservacionistas dos solos e de economia da água. 
De grande importância seria a reformulação do sistema de crédito agrícola, que deveria continuar a ser subsidiado, mas destinado sobretudo à manutenção da família do aaricultor durante a entre-safra. Esta medida teria grande imoortấncia, sobretudo para os pequenos produtores, porque o grande problema que eles enfrentam é o da aquisição de alimentos na entre-safra. É justamente neste perfodo que eles recorrem aos agiotas, fazerido empréstimos por juros muito elevados e vendendo a produção antecipadamente, "na folha", a preços muito baixos. Ficando endividados, se não venderam a produção na folha, são obrigados a fazê-lo logo no inf́cio da colheita, quando os preços estão deteriorados. Um sistema de empréstimos oficiais a juros baixos, que não os obrigasse a empregar um grande percentual na aquisiçâa de adubos e a uma organização, através de cooperativas, teria muito mais influência em favor do pequeno produtor do que a elevação da produtividade com a aplicação de adubos caros e de inseticidas e fungicidas. Esta política de crédito deveria ser acompanhada ainda de uma sólida política de assistência técnico-agronômica, a fim de que o agricultor cultivasse na ocasião própria o produto necessário, dispondo de boas sementes e de conselhos técnicos. Os estudos de mercado deveriam ser permanentemente repetidos, a fim de evitar um descompasso entre a oferta e a procura dos alimentos produzidos. Agro-indústria de conservação da produção agrícola, como a liofilização da cebola, deveriam também ser implantadas, ficando sob o controle de associações de produtores.

A agricultura irrigada tem um grande futuro no Nordeste, sobretudo, se conhecendo as possibilidades de utilização das águas do São Francisco e do Parnaíba, rios caudalosos e perenes, e dos açudes e grandes represas construídos pelo IFOCS e pelo DNOCS. Mas a irrigação deve ser feita com técnicas bem adaptadas às condições mesológicas, técnicas de baixo custo, com economia de água e com preservação da qualidade dos solos, pois são do conhecimento geral os perigos de salinização dos solos em áreas tropicais irrigadas. Uma politica de água nä̀o deve esquecer a grande importância que têm os poços artesianos e os reservatórios que acumulam a água da chuva. A conservação da vegetação natural, sobretudo naqueles pontos em que há uma maior facilidade de obtenção de água, ora pela condensação superficial - o orvalho da Serra Negra em Pernambuco alimenta uma floresta de grande porte, considerada por alguns botânicos como semelhante à floresta amazônica - ora pela conservação da água em lençóis subterrâneos em áreas de rochas sedimentares - caso do Araripe em sua vertente do Norte cearense.

E verdade que existem grandes áreas do sertão semi-árido que não podem ser irrigadas, face à sua localização distante dos rios e dos açudes. Para estas áreas se poderia estimular, como advogava o grande agrônomo e naturalista Guimarães Duque, o desenvolvimento das plantas xerófitas, plantas adaptadas aos climas mais rigorosos, algumas de cultura permanente como o algodão arbóreo, a algaroba e algumas leguminosas típicas da caatinga e que servem de excelente ali- 
mento para o gado. $\mathrm{O}$ algodão arbóreo de fibra longa se adapta até a regiốes com expressiva aridez, onde chove menos de $400 \mathrm{~mm}$ por ano, podendo fornecer matéria prima de primeira qualidade à indústria têxtil, hoje agonizante no Nordeste. A algaroba, planta originária dos desertos andinos, pode ser utilizada como alimento suplementar para o gado, fornecendo uma serie de subprodutos. Mas não são apenas as xerófitas permanentes que podem ser cultivadas com grande sucesso nas regiões secas. Nelas também tem grande utilidade a cultura de cereais de ciclo vegetativo curto como o sorgo, que é a base alimentar das populações que vivem nas regióes do Oeste dos Estados Unidos, da Índia e da China, onde o mesmo é cultivado e usado como alimento para o homem e para os animais. Ao lado do sorgo, ainda se pode cultivar, com sucesso, no Semi-árido; o amendoim, o milhete, a mamona e, em certas regiões, a mandioca. É necessário que se estimulem estas culturas nas áreas favoráveis às mesmas e se assistam aos pequenos e médios produtores.

De importância capital, é a organização do sistema de comercialização, a fim de extinguir o intermediário e facilitar o trânsito da produção desde o produtor até o consumidor, através da ação de cooperativas ou de sociedades governamentais.

\section{PRÉ-REQUISITOS PARA TRILHAR AS VIAS APONTADAS}

Não pretendemos ter dado as soluções para a problemática nordestina, visando a quebra de desequilíbrio e de estrangulamentos, como um pacote mágico e eficiente. Apenas apontamos caminhos que devem e podem ser seguidos, após serem examinados e discutidos com as populações da região, através das instituições da sociedade civil, sobretudo das associações corporativas e de classe. Isto porque tememos que soluções feitas de cima para baixo e impostas aos agentes diretamente interessados na produção, na industrialização e na comercialização, não tenham alguma influência. Isto porque qualquer solução formulada por técnicos, baseada em conhecimentos adquiridos em compêndio, que formulam esquemas gerais, baseados em experiências de outras áreas, está fadada ao fracasso e à inexequibilidade, por serem realmente inexequiveis ou porque encontrarão uma oposição, nem sempre explícita, mas real à sua execução. As soluções para os problemas que atingem o povo só podem ser efetivas se na seleção e na estruturação, isto porque a população não deve ser nunca encarada como objeto, mas, ao contrário, como sujeito do processo de modificação do desenvolvimento. 